\title{
Meio urbano e mudanças climáticas - estudo de caso do município de Castro, PR
}

\author{
Carlos Mello Garcias \\ Engenheiro civil, professor do curso de Engenharia Ambiental e \\ do Programa de Pós-Graduação em Gestão Urbana da Pontifícia \\ Universidade Católica do Paraná (PUCPR), Rua Imaculada \\ Conceição 1155, Prado Velho - PUCPR, Curitiba, PR, CEP 81650- \\ 270, (41)3271-1598, carlos.garcias@pucpr.br

\section{Consuelo Marques da Silva} \\ Engenheira ambiental, mestranda do Programa Master \\ Eco-Polis, Università degli Studi di Ferrara, Rua Francisco \\ Anacleto da Fonseca, 749, Castro, PR, CEP 84172-040, \\ consumarques@gmail.com
}

\begin{abstract}
Resumo
O objetivo do texto é chamar a atenção para a dimensão especular da relação sujeito-espaço edificado. Trabalha-se com a hipótese de que, a partir de uma experiência essencialmente subjetiva, a arquitetura se oferece como espelho e, ao fazê-lo, desempenha papel essencial na constituição do sujeito. As referências teóricas vêm da arquitetura (Quatremère de Quincy) e da psicanálise (Lacan). Conclui-se o texto argumentando que a dimensão imaginária da arquitetura abre possibilidades de pesquisas tão incipientes quanto fascinantes na teoria da arquitetura.
\end{abstract}

Palavras-chave: mudanças climáticas, meio urbano, Castro-PR, gases de efeito estufa. tema Mudança do Clima e suas conseqüências já faz parte da realidade política e econômica internacional, com repercussão em diversas áreas, afetando diretamente a vida das pessoas, atividades econômicas e o próprio equilíbrio dos recursos da biodiversidade. Este assunto vem ocupando um espaço cada vez maior nas preocupações das sociedades, tratando-se de um dos problemas mais relevantes atualmente, com impacto direto a vida humana no planeta (MCT, 2008).

O modo de vida moderno, juntamente com a queima de combustíveis fósseis de forma descontrolada, vem contribuindo para que essas mudanças ocorram de forma não natural. O aquecimento global, que é um fenômeno natural, vem sendo influenciado pelos gases lançados na atmosfera pelas atividades antrópicas.

Segundo Walker e King (2008), à medida que se aumenta a concentração dos gases do efeito estufa
(GEE) na atmosfera, o calor extra que eles capturam leva a um aquecimento global forçado, que exerce uma pressão sobre o sistema climático do planeta e que pode provocar as mudanças climáticas. A superfície terrestre encontra-se em um aquecimento cada vez mais acelerado, e os padrões climáticos vêm saltando de um estado estável para outro desconhecido.

Dentro deste contexto, torna-se necessário avaliar a principal fonte de contribuição para as mudanças climáticas: o meio urbano. De acordo com Ribeiro (2006), os núcleos urbanos são responsáveis pela emissão de cerca de 90\% do monóxido de carbono, e aproximadamente, $80 \%$ do dióxido de enxofre, além da intensidade verificada na emissão de vários tipos de efluentes e nos demais tipos de degradação ambiental.

As áreas urbanas ocupam menos de $2 \%$ da superfície da Terra, porém abrigam $50 \%$ da população do 
mundo. Por estas e outras razões, as cidades estão na linha dianteira na resposta às ameaças da mudança do clima (HALL et al., 2009). Para Flannery (2007), as cidades são vitais para a civilização, e, no entanto, são entidades frágeis, vulneráveis às tensões trazidas pelas mudanças climáticas. É, portanto, importante considerar as cidades em relação ao fornecimento de suas necessidades básicas - comida, água e energia. O meio urbano apresenta, desde a sua formação, características que levam ao desequilíbrio, e a identidade de um meio dependente de interligações com outras áreas da cidade, e muitas vezes, para que suas necessidades sejam supridas, outras áreas são também prejudicadas (RIBEIRO, 2006).

Para o melhor entendimento desta relação da contribuição do meio urbano nas mudanças climáticas, será feito um estudo de caso no município de Castro, Paraná, com a análise dos setores que mais contribuem para as emissões no local. A percepção ambiental da população também será avaliada, através da aplicação de um questionário semi-estruturado sobre a ocorrência de mudanças climáticas locais.

Sendo assim, o objetivo geral do trabalho é avaliar a percepção da população e as possíveis contribuições do meio urbano nas mudanças climáticas.

\section{Mudanças Climáticas}

A partir da Conferência do Rio de Janeiro, a chamada ECO-92, em 1992, a Comunidade Internacional tem se empenhado em entender este amplo complexo relacionado à mudança do clima. Foi estabelecida a Convenção do Clima, e no seu âmbito, o Protocolo de Quioto, que define mecanismos de mercado que, de forma inédita no cenário internacional, tentam enquadrar responsabilidades e obrigações das diversas partes, abrindo oportunidades de desenvolvimento social econômico sustentável (MCT, 2008).

O relatório do Painel Intergovernamental de Mudanças Climáticas (IPCC) (2007), utilizando bases de informação e metodologias computacionais de modelagem climáticas mais apuradas, diminuiu significativamente as incertezas quanto ao acontecimento real das mudanças climáticas. Carmo (2008) ressalta que o relatório propõe uma elevação da temperatura que pode chegar a $5^{\circ} \mathrm{C}$ até o final do Século XXI, e que essas mudanças estão em grande parte associadas a emissões decorrentes de atividades humanas. Esse aumento da temperatura é causado pelas emissões antrópicas acumuladas de gases de efeito estufa, principalmente o Dióxido de Carbono $\left(\mathrm{CO}_{2}\right)$, oriundo da queima de combustíveis fósseis também no setor de transportes, o Metano $\left(\mathrm{CH}_{4}\right)$ e o Óxido Nitroso $\left(\mathrm{N}_{2} \mathrm{O}\right)$, sobretudo proveniente das atividades agropecuárias.

De acordo com Monzoni (2009), cerca de 71\% da energia consumida atualmente no setor de transporte é proveniente de combustíveis fósseis não renováveis, com alto nível de emissão de GEE. A participação do setor de transportes nas emissões totais de $\mathrm{CO}_{2}$ por atividades energéticas no Brasil no ano de 2006 foi de $42 \%$. O fato de as cidades estarem planejadas visando apenas o transporte por veículos automotores, sem espaço para o transporte alternativo, é um agravante das emissões.

A destinação dos resíduos sólidos é um outro sério problema enfrentado pelo Brasil e diversos outros países. Esse é um fator que necessita de muita atenção, por apresentar o maior déficit e por representar o maior problema ambiental. Somente cerca 36\% do lixo coletado é encaminhado a aterros sanitários no país (NAE, 2005). A destinação dos resíduos contribui perigosamente para o efeito estufa, seja em lixões, aterros controlados ou em aterros sanitários, os resíduos sólidos entram em decomposição pela ação de microorganismos, que durante o processo de biodigestão transformam o material depositado em líquidos e uma série de gases, em especial o $\mathrm{CO}_{2}$ e o $\mathrm{CH}_{4}$, mistura conhecida como biogás (MONZONI, 2009).

O IPCC estima que as emissões de $\mathrm{CH}_{4}$ provenientes de aterros representam de 6 a 20\% das emissões totais globais de metano por fontes antropogênicas. O inventário brasileiro de emissões afirma que entre os anos de 1990 e 1994, o país emitiu aproximadamente 800 mil toneladas de metano por ano pela decomposição de resíduos sólidos em aterros e/ou lixões (MONZONI, 2009).

\section{Concentração de Gases de Efeito Estufa e Aquecimento Global}

O aquecimento global é um fenômeno climático de larga extensão. Um aumento da temperatura 
média superficial global que vem acontecendo nos últimos 150 anos. Grande parte da comunidade científica acredita que o aumento de concentração de poluentes de origem humana na atmosfera é causa do aquecimento global, que potencializa o efeito estufa natural do Planeta. A Terra recebe radiação emitida pelo Sol e devolve grande parte dela para o espaço através de radiação de calor. Os poluentes atmosféricos retêm uma parte dessa radiação que seria refletida para o espaço, em condições normais. Essa parte retida causa um importante aumento do aquecimento global. Denomina-se efeito de estufa à absorção, pela atmosfera, de emissões infravermelhas impedindo que as mesmas escapem para o espaço exterior (WALKER e KING, 2008). $\mathrm{O}$ que vem acontecendo nos dias atuais foge dessa "condição normal", pois a retenção desses gases é maior que a sua reflexão para o espaço, causando um desequilíbrio e conseqüentemente, o aquecimento.

Para Flannery (2007, p. 52):

"Existem em torno de trinta gases do efeito estufa na atmosfera, todos presentes em pequenas proporções e cujo efeito, para maioria dos propósitos, é medido tendo o $\mathrm{CO}_{2}$ como referência (ou seja, sendo convertidos em "unidades de $\mathrm{CO}_{2}$ nas equações científicas). A maioria é tão rara que parece desprezível, e, no entanto, absorvem calor em diferentes comprimentos de onda, qualquer aumento no volume é significativo. Pense neles como clarabóias de vidro em um telhado, cada gás representando uma clarabóia diferente. Eà medida que essas janelas aumentam mais energia luminosa é admitida na sala, para ser aprisionada como calor."

Walker e King (2008) explicam que apesar de a atmosfera conter um grande número de gases do efeito estufa, os mais importantes são $\mathrm{CO}_{2}, \mathrm{CH}_{4} \mathrm{e}$ vapor d'água. Estes gases são de grande importância para a vida dos seres vivos. O $\mathrm{CO}_{2}$, diferente do que muitos pensam, é um gás que desempenha um papel vital, evitando que sejamos congelados, ou em sua falta, fiquemos superaquecidos. Essa é sua função natural. Porém, sua existência em excesso, pelas emissões antropicas faz com que ele maximize os efeitos de aquecimento. $\mathrm{O} \mathrm{CO}_{2}$ é o mais abundante dos gases do efeito estufa e é produzido sempre que ocorre queima de matéria ou quando alguma matéria se decompõe (FLANNERY, 2007).
$\mathrm{O} \mathrm{CO}_{2}$ começa a ficar perigoso em grandes proporções, pois embora escasso e fraco na sua capacidade de reter calor, este gás tem um tempo de permanência muito longo na atmosfera: em torno de $56 \%$ de todo o $\mathrm{CO}_{2}$ que já foi liberado pelas atividades antrópicas ainda permanece no ar, o que é a causa direta e indireta de aproximadamente $80 \%$ de todo o aquecimento global. Além disso, este gás se combinado com o vapor d'água, faz a atmosfera reter mais umidade, elevando ainda mais a temperatura (FLANNERY, 2007).

O gás metano $\left(\mathrm{CH}_{4}\right)$ é outro que merece destaque. Depois do $\mathrm{CO}_{2}$, é um dos gases mais significativos para o aquecimento global. Este gás é 60 vezes mais eficiente para captar o calor que $0 \mathrm{CO}_{2^{\prime}}$ porém, permanece poucos anos na atmosfera. Ele se forma a partir da decomposição anaeróbia dos microorganismos, e é estimado em 15\% a 17\% de todo o aquecimento global neste século (FLANNERY, 2007). Apesar de ser um dos mais perigosos gases, sua biomassa gerada pode ser reutilizada, servindo de energias alternativas para muitas empresas, podendo servir para neutralizar suas emissões.

Além desses gases, Flannery (2007) destaca a presença do óxido nitroso $\left(\mathrm{N}_{2} \mathrm{O}\right)$, que é 270 vezes mais eficaz que o $\mathrm{CO}_{2}$ na absorção da radiação e, apesar de ser mais raro que o metano, permanece 150 anos na atmosfera.

Cerca de um terço de todas as emissões vem da queima de combustíveis fosseis, e o resto, da queima de biomassa e do uso de fertilizantes que contem nitrogênio. Outros gases mais raros, como os da família dos HFC e CFC, são gerados a partir das invenções humanas, criados a partir de processos industriais. Estes gases são altamente significativos para o aquecimento global, pois são mil vezes mais potentes para captar calor que o $\mathrm{CO}_{2}$, podendo permanecer séculos na atmosfera terrestre (FLANNERY, 2007).

\section{Cidades, população e mudanças climáticas}

Para entender sobre a influência das cidades nas mudanças climáticas atuais, é necessário compreender a evolução do processo urbano e como se deram as relações sociedade-meio ambiente para a formação da estrutura das cidades. A evolução urbana mundial 
iniciou-se com as primeiras cidades da Mesopotâmia, seguindo com as cidades ao longo do vale do Nilo, estendendo-se à Região Mediterrânea e chegando à China. "Em todas essas regiões, nasceram, cresceram e desapareceram cidades, mas a vida urbana, uma vez estabelecida, nunca chegou a desaparecer" (PALSULE, 2004, p.36).

Sjoeberg (1972, p.43) afirma que

"A cidade, de diversas maneiras, funcionava como um incentivo ao progresso. Muitas das primeiras cidades surgiram em estradas importantes; novas idéias e invenções, naturalmente, convergiam para elas. Elas eram centros de maior prestígio, onde se concentravam os edifícios religiosos e governamentais. Tal concentração tinha dupla importância: pela dificuldade de comunicações, a proximidade dos membros da elite facilitava a troca de idéias e, ao mesmo tempo, dava à classe dominante a máxima proteção contra ataques externos."

A concentração de serviços na cidade levou a uma evolução urbana gradual. Para Sjoeberg (1972) só é possível interpretar e entender corretamente o curso desta evolução urbana se a compararmos com a evolução tecnológica e à evolução social da humanidade, sendo estas as bases do desenvolvimento urbano, e que contribuíram para a expansão das cidades. O advento da industrialização trouxe significativa melhoria nos implementos e técnicas agrícolas, permitindo a preservação dos alimentos e também melhorando aspectos de transporte e comunicação. O aperfeiçoamento dos sistemas de tratamento de água e de coleta de esgoto permitiu que mais pessoas se concentrassem nos centros urbanos. O grande centro urbano substituiu o meio rural como constituinte da base da economia da cidade. As cidades cresceram em tamanho, população e importância, e o mesmo aconteceu com os problemas de poluição. Gradativamente, o sucesso da evolução tecnológica e da Revolução Industrial começou a levar ao aumento da escassez de terras, de vida selvagem, e principalmente, de recursos e combustíveis. Mas mais importante do que isso, o que ficou realmente ameaçado por esta nova era tecnológica foi a capacidade do meio ambiente absorver os impactos resultantes desta nova modalidade da existência humana (PALSULE, 2004).
Mota (1999) explica que o meio ambiente natural exerce influências sobre o processo do crescimento urbano, através de características que são favoráveis ou não. Por outro lado, o processo de urbanização provoca alterações no meio ambiente que compromete suas características. Alguns fatores, como condição climática local, relevo, recursos hídricos e cobertura florestal, entre outros, são características de um ambiente que se relaciona com a urbanização, influenciando no processo ou sendo modificado por ele.

Para Pereira (2001, p.35):

"Ao produzir o espaço urbano, a sociedade se apropria da natureza e a transforma, criando mercadorias desejáveis e indesejáveis. As mercadorias desejáveis fazem parte do desenvolvimento, como serviços, objetos, equipamentos em geral, enquanto que as mercadorias indesejáveis são aquelas que não foram devidamente planejadas, consideradas desvios dos modelos de desenvolvimento: automóveis poluidores, excesso de resíduos e sub-habitações."

Por estes e outros fatores, as cidades então se tornaram quase que vilões do meio ambiente onde se inseriram. Hoje em dia, as conseqüências desse processo inadequado de crescimento já são comuns na maioria dos centros urbanos: falta de condições mínimas de saneamento, destruição de recursos com valor ecológico, condições precárias de habitação e a poluição do meio ambiente. Nas cidades, as ações do homem ocorrem de forma intensa e rápida, provocando modificações, muitas vezes irreversíveis, com prejuízos para o ambiente e para si próprio (MOTA, 1999).

Dentre estas modificações irreversíveis causadas pelas ações humanas, as mudanças climáticas mostram-se intimamente ligadas ao meio urbano e ao modo de vida das pessoas que nele habitam. Segundo Carmo (2007), a população urbana no Brasil aumentou mais de 130 milhões de pessoas entre os anos de 1950 e 2000. A urbanização está ligada ao aumento de emissões dos GEE pelo crescimento do uso de energia que este meio necessita. (HOGAN, 2009).

Segundo Ribeiro (2006), 85\% das emissões de $\mathrm{SO}_{2^{\prime}} \mathrm{e}$ a sua contribuição para a formação da chuva ácida, 
95\% dos lançamentos de CO e $80 \%$ das emissões de $\mathrm{CO}_{2}$ ocorrem em áreas urbanas. $\mathrm{E}$ toda essa emissão é concentrada especialmente na mesma área onde se concentram também populações expostas aos mesmos.

Levando-se em conta que mais de $80 \%$ dos brasileiros viveram em cidades em 2000, será nelas que o impacto das mudanças climáticas será mais sentido, e se for considerado que os padrões de comportamento urbano, tais como valores, estilos de vida e consumo, são difundidos primeiramente sobre a sociedade maior, é nas cidades que os novos valores e práticas terão de iniciar (HOGAN, 2009). E se for considerado ainda o acúmulo e histórico de problemas ambientais e o atraso na criação de uma infra-estrutura ambiental focada no crescimento sustentável das cidades, elas não estão preparadas hoje para a mudança climática.

De acordo com Flannery (2007, p.242):

O esgotamento da base de recursos é o principal motivo de fracasso até mesmo das grandes sociedades [...]. No que se referem às mudanças climáticas, as cidades se parecem mais com plantas do que com animais, pois são imóveis e dependem de intricadas redes para o fornecimento de água, comida e energia de que necessitam."

A discussão das políticas de mudanças climáticas na escala das cidades está ganhando espaço, ainda que focadas apenas na remediação dos riscos crescentes ao invés da avaliação dos impactos e análises com vistas à adaptação, ainda que a prevenção seja a forma mais econômica e efetiva no enfrentamento de problemas, reduzindo também impactos sociais como mortes e pessoas desabrigadas. (HUNT; WATKISS, 2007 apud NUNES, 2009).

Segundo Ojima (2009), se forem consideradas as medidas de mitigação e adaptação, as cidades são os principais pontos vulneráveis e de tensão quanto às mudanças climáticas, pois ao mesmo tempo em que são os principais contribuintes para as emissões de GEE, são elas que possuem as melhores condições para potencializar o desenvolvimento de alternativas para a melhoria das condições de vida da população, bem como alternativas de mitigação dos efeitos danosos que as mudanças do clima podem trazer para o meio urbano.
No meio urbano, a segmentação e a diferenciação social, demográfica, econômica e ambiental caracterizam um padrão de expansão acelerado que propicia maior vulnerabilidade da população face às mudanças climáticas (NUNES, 2009).

A vulnerabilidade, neste caso, que vai além das questões ambientais, é chamada de vulnerabilidade socioambiental. Para Alves (2009, p.82):

"Vulnerabilidade socioambiental é a coexistência ou sobreposição espacial entre grupos populacionais muito pobres e com alta privação (vulnerabilidade social) e áreas de risco ou degradação ambiental (vulnerabilidade ambiental)."

Ehrlich e Holdren (1971 apud MELLO, 2009) apontaram o tamanho da população, assim como seu ritmo e padrão de crescimento, como o mais importante fator gerador de impacto ambiental. Sendo assim, torna-se essencial analisar aspectos populacionais dentro de um ambiente urbano, uma vez que a população é uma das principais bases sobre as quais se alicerçam os modelos de desenvolvimento (MELLO, 2009). O aumento da afluência das populações mais pobres pode ter reflexos importantes em termos de demanda por energia e recursos ambientais (HOGAN, 2001; SAWYER, 2002 apud (ARMO, 2007). Segundo Nunes (2009) as mudanças climáticas aumentariam a pobreza, pois os eventos extremos afetariam a produtividade agrícola, elevando o preço dos alimentos.

Ribeiro (2006, p.96) destaca que:

"A exclusão social força a determinadas ações nada ecológicas, como a ocupação em áreas de preservação rigorosa ou áreas de risco, ou ainda, em certos casos, de desgaste excessivo dos recursos naturais, além de outras formas predatórias. [...] A riqueza concentrada, por sua vez, leva a um consumismo excessivo, a um maior consumo de recursos naturais, inclusive para a construção da tessitura urbana e, ainda, produzem muito mais resíduos. [...] Portanto a distribuição injusta da riqueza provoca resultados nocivos e leva, sistematicamente à insustentabilidade do sistema urbano."

Para Nunes (2009), o grau de risco e o tipo de perigo ao qual uma pessoa é sujeita estão fortemente 
condicionados aos seus padrões de renda. Nesse sentido, a identificação dos grupos sociais mais vulneráveis a estes riscos ambientais constituise em uma das mais importantes contribuições para aumentar a capacidade de enfrentar as decorrências das mudanças ambientais globais (CARMO, 2007).

A ocupação irregular de áreas vulneráveis causada pela exclusão social de grupos populacionais é um fator de exposição ao risco que deve ser prevenida, já que estes lugares são os mais sensíveis e sujeitos a riscos. Nunes (2009) destaca que uma ocorrência só é catastrófica quando afeta grupos humanos, deixando desabrigados, feridos, mortos e prejuízos econômicos; assim, enchentes não causariam desastres, por exemplo, se a ocupação de planícies inundáveis fosse evitada, e processos de movimento de massa não seriam trágicos se a população não ocupasse as encostas.

Hunter (2000 apud MARANDOLA, 2009) aponta três formas de como os fatores demográficos interferem nas mudanças climáticas: 1. Contribuição na emissão dos gases do efeito estufa; 2 . Mudanças no uso da terra; e 3. No consumo.

Tem-se maior intensidade de contribuição nas emissões de gases do efeito estufa pela queima de combustíveis fósseis, principalmente pelos combustíveis de automóveis, e as emissões industriais. A expansão urbana historicamente gerou um sistema de transporte que depende de automóveis, conseqüentemente, com emissões significativas de $\mathrm{CO}_{2}$ (HOGAN, 2009). Ribeiro (2006) afirma que nos últimos 50 anos os automóveis movidos a combustíveis derivados do petróleo superaram as indústrias no nível de emissão de poluentes, sendo hoje o principal poluidor do meio urbano, com o fato agravante de que convive de forma mais próxima com os ambientes utilizados com o ser humano dentro de uma cidade.

Quanto as mudanças no uso da terra, estas estão ligadas ao desmatamento histórico e intensificação da agricultura para o atendimento dos habitantes urbanos (RIBEIRO, 2006). O espaço e a natureza, vistos como recursos a serem apropriados, são encarados como inesgotáveis, não se respeitando a capacidade de suporte do meio ambiente (NUNES, 2009).
Já o consumo tem caráter fundamental de influência individual do ser humano num aspecto ambiental mundial como as mudanças climáticas, pois não se trata exatamente de quantas pessoas existem, mas como é o seu consumo individual (OJIMA, 2009). Estes estão intimamente ligados à industrialização que reorganizou a ordem mundial durante a Revolução Industrial, mudando padrões de produção. Para Mello (2009, p.109):

"Os padrões de produção sempre foram considerados os grandes vilões ambientais, sendo constantemente acusados tanto de poluir demais o ambiente, quanto de estimular e sustentar padrões excessivos de consumo, de não serem eficientes o suficiente ou de manipularem padrões de qualidade e legislações em função da maximização dos lucros e em detrimento da saúde e do bem estar humanos."

Por todos os aspectos observados anteriormente, as cidades são tidas como causadoras de impactos e poluições, e sua imagem de principal contribuinte na emissão de GEE fez com que as atenções se voltassem a elas. Porém, quando os impactos começam a ser sentidos e a sociedade se vê frente a uma mudança que pode ocorrer de forma catastrófica, a cidade torna-se uma vítima, que precisa de ajuda para conter os prejuízos causados pela falta de planejamento e estruturação urbana.

\section{Metodologia}

Para o desenvolvimento do presente estudo foram utilizados os materiais obtidos de pesquisa bibliográfica sobre as mudanças climáticas, realizados em livros, artigos científicos e sites relacionados ao tema.

Assim, este Estudo de Caso se propôs analisar as emissões atmosféricas de gases de efeito estufa provenientes do meio urbano do município através de estimativas de emissões produzidas nos setores de transporte, tratamento de resíduos sólidos e efluentes, e a contribuição destes para as mudanças climáticas. Pela aplicação de um questionário semiestruturado, foi feita a análise da percepção dos moradores locais quanto às mudanças climáticas no município. Desse modo, as fases de construção deste estudo são compostas por: 
Fase 1: Revisão Bibliográfica. Nesta fase foi feita a fundamentação teórica do estudo, composta pela pesquisa em artigos, livros e outros materiais, sobre os temas relevantes para o desenvolvimento do estudo de caso.

Fase 2: Estudo de caso.

a. Identificação da área de estudo: Nesta fase foi caracterizado o meio onde o estudo de caso foi realizado: o município de Castro - PR, abordando localização, histórico e aspectos demográficos, geográficos e econômicos.

b. Aplicação: Esta fase foi composta pela aplicação do estudo de caso, onde foi feita a análise das contribuições do meio urbano do município nas mudanças climáticas por meio de duas fases:

1. Estimativa das emissões e pela aplicação de um questionário semi-estruturado de percepção da população local quanto às mudanças climáticas do local, numa amostra de 150 entrevistados;

2. Análise das emissões de gases de efeito estufa do município (transporte, resíduos e efluentes). Quanto à quantificação das emissões provenientes dos combustíveis de veículos, Sattherwaite (2008) afirma que existe certa dificuldade quanto aos veículos das pessoas que moram em um lugar e trabalham em outro. Estas emissões deveriam ser atribuídas ao local onde as pessoas trabalham ou ao local onde elas moram? Neste trabalho serão usados os dados dos anuários estatísticos do DETRAN/PR (Departamento de Trânsito do Paraná) que consideram os veículos registrados no município anualmente.

Fase 3: Análises dos Resultados. Para a Fase 3 foram analisados os resultados obtidos nas fases anteriores e discutidos a importância destes para a conclusão do trabalho.

Estudo de Caso: Município de Castro, Paraná

\section{Caracterização}

O município de Castro está localizado na região paranaense denominada Campos Gerais, numa posição de transição entre o Primeiro e o Segundo Planalto, estando a $988 \mathrm{~m}$ acima do nível do mar (PARANÁ, 2010). Castro está inserido na Bacia Hidrográfica do Rio Tibagi, tendo como sub-bacias em seu território a Bacia Hidrográfica do Rio lapó, Bacia Hidrográfica do Rio Ribeira e a Bacia Hidrográfica do Rio São Cristóvão. O município possui área territorial de 2.533,247 km² (ITCG, 2008 apud IPARDES, 2009). São municípios limítrofes de Castro: Piraí do Sul, Ponta Grossa, Carambeí, Campo Largo, Cerro Azul e Tibagi (IPARDES, 2009).

A população do município é de 65.496 habitantes, sendo, deste total, 43.250 da área urbana e 20.331 da área rural (IBGE, 2007). A estimativa populacional do ano de 2009 apontou 68.071 habitantes (IBGE, 2009 apud IPARDES, 2009). A distribuição etária da população pode ser considerada equilibrada, tendendo para uma população jovem. A faixa populacional composta por pessoas até 20 anos de idade é constituída por 25.176 habitantes; na faixa etária de 20 a 40 anos, existem 20.968 habitantes; e os habitantes acima de 40 anos somam o total de 18.722 pessoas (IBGE, 2007 apud IPARDES, 2009).

\section{Contribuições do meio urbano do município para as Mudanças Climáticas}

Quantificar as emissões de um meio urbano e estimar sua provável contribuição para as mudanças climáticas globais não é um trabalho fácil. A influência e a interferência de um meio a outro não se atém aos limites políticos já estabelecidos. A área necessária para que se desenvolva uma cidade também vai muito além destes limites, pois esta necessita de recursos que não dispõe em seu território, precisando retirálos de locais distantes para abastecê-la. Monzoni (2007) afirma que as emissões provenientes de atividades humanas que geram GEE possuem duas naturezas básicas: uma relacionada à energia (sua geração, transformação, utilização em processos industriais e transporte) e outra chamada de nãoenergética (mudanças de uso do solo, agricultura e resíduos).

No estudo de caso para este trabalho, foi feita a análise das emissões provenientes dos setores de transporte, tratamento de resíduos sólidos e efluentes, com base nos dados e observações referentes ao município de Castro - PR, mais especificamente sua 
área urbana. A análise das emissões industriais dentro do município não é significativa, visto o pequeno número de indústrias existentes; porém não deve ser ignorada. Ficará esta para um trabalho futuro.

Para a caracterização da consciência da população urbana municipal quanto às mudanças climáticas, foi aplicado um questionário semi-estruturado, cujos resultados também serão apresentados a seguir.

Setor de Transportes

Em Castro nota-se que pouquíssimas pessoas usam o transporte público, e a grande maioria utiliza veículos particulares. Da análise de dados do DETRAN nos anos de 2005 a 2009, há a constatação de que o crescimento da frota no município de Castro é de 1.700 veículos ao ano. No ano de 2008, por exemplo, o município de Castro possuía no total 22.224 veículos. Destes, 12.066 automóveis, 189 ônibus, 1.415 caminhões e 2.940 caminhonetes e camionetas, etc. Utilizando-se do número de automóveis municipais e relacionando com a proporção paranaense de que $66,7 \%$ dos veículos do Paraná são movidos a gasolina, teremos aproximadamente 8.048 automóveis no município movidos a gasolina. Considerando o tamanho da área urbana do município e as distâncias percorridas geralmente pela população que se utiliza do carro, se cada carro movido a gasolina percorrer diariamente $10 \mathrm{~km}$, cada carro emitirá aproximadamente 1,58 $\mathrm{kg}$ de $\mathrm{CO}_{2}$, resultando numa emissão total de aproximadamente $12 \mathrm{t}$ de $\mathrm{CO}_{2}$ No caso de um ônibus urbano, 200 km percorridos por este veículo equivale a uma emissão de 40,890 t de $\mathrm{CO}_{2}$ (IPCC/ BEM apud SEMA, 2009).

Esses dados usados para exemplificar as emissões dos transportes e sua contribuição na emissão de $\mathrm{CO}_{2}$, nos dão idéia da significância da participação deste setor para as mudanças climáticas e sua interferência em um meio urbano. O investimento em transporte alternativo e também no transporte coletivo torna-se viável para reduzir estas emissões.

Tratamento de resíduos sólidos

O município de Castro conta com um aterro sanitário em funcionamento desde o ano de 2003, atualmente sob regime de consórcio intermunicipal com o município de Piraí do Sul. De acordo com o Plano de Gerenciamento de Resíduos Sólidos do Município (PGRS) (PARANÁ, 2010) a geração per capta de lixo municipal é de 0,536 kg/hab/dia. A composição física percentual (média) dos resíduos sólidos urbanos de Castro fica da seguinte maneira: 52,5\% orgânicos, 24,5\% papel, 2,3\% latas, 2,9\% plásticos, 1,6\% é composto por vidros e $16,2 \%$ de materiais diversos. Ainda de acordo com informações do documento, a geração diária de resíduos do município é de 20 toneladas diárias. Destas, 10,5 toneladas são de matéria orgânica, 4,9 toneladas de papel/papelão, 0,58 toneladas de plástico, 0,46 toneladas de metal, 0,32 toneladas de vidro e 3,2 toneladas de rejeito. 45.000 habitantes da zona urbana são atendidos pela coleta.

Por esses dados é claro que se houvesse destinação adequada às 20 toneladas geradas ao dia, apenas 3,2 toneladas seriam destinadas ao aterro municipal, diminuindo consideravelmente as emissões provenientes do aterro.

Não existem dados sobre a emissão resultante da destinação dos resíduos desde que o aterro municipal foi implantado, no ano de 2003. Porém, no período de 1990 a 2004 onde a destinação era feita em lixão a céu aberto, a emissão ficou em torno de 220 t de $\mathrm{CO}_{2} / a n o$ ao ano. Sabe-se que a destinação em aterros sanitários emite mais $\mathrm{CH}_{4}$ que a destinação de resíduos em lixões, portanto, a emissão proveniente do tratamento de resíduos aumentou significativamente desde o ano em que o aterro foi implantado.

Tratamento de efluentes

Os efluentes com um alto teor orgânico têm um grande potencial de emissão de $\mathrm{CH}_{4}$ na sua fase de tratamento, em especial os esgotos domésticos e comerciais, e os efluentes das indústrias de alimentos, bebidas, papel e celulose. No caso dos esgotos domésticos, em função do elevado conteúdo de nitrogênio na alimentação humana, ocorrem ainda as emissões de $\mathrm{N}_{2} \mathrm{O}$ (MCT, 2009).

Em 1990, 9\% das emissões de $\mathrm{CH}_{4}$ no Brasil eram do setor de tratamento de efluentes. No ano de 2005, este valor subiu para 11\% (MCT, 2009). Segundo o IPCC (2001), o fator de emissão de $\mathrm{N}_{2} \mathrm{O}$ das ETE's (Estação de Tratamento de Esgoto) é de $3,2 \mathrm{~g} \mathrm{~N}_{2} \mathrm{O}$. pessoa ${ }^{-1}$. ano ${ }^{-1}$. Se forem considerados 
43.000 habitantes do meio urbano com esgoto coletado e tratado, a emissão proveniente da ETE será de 137,6 kg N $\mathrm{O}_{2}$. $\mathrm{ano}^{-1}$.

O tratamento de esgoto municipal é anaeróbico RALF (reator anaeróbio de leito fluidizado), e 74,84\% da população é atendida por coleta e tratamento (100\% do esgoto coletado é tratado) (SANEPAR, 2010). O tratamento anaeróbico do esgoto é um grande gerador de metano, e o fato de a ETE do município não contar com um queimador de suas emissões ou nenhum tipo de aproveitamento, aumenta ainda a contribuição desta fonte para as emissões de GEE no município.

Análise perceptiva da população - Aplicação do questionário semi-estruturado

Para Oliveira (2005, apud PASCOALINO E PITTON, 2007, p.3), "a percepção climática pode ser entendida como a apreensão pessoal das condições atmosféricas sobre um dado lugar ligando-se, portanto, a sensações, ao psicológico e ao sociológico".

A aplicação do estudo de percepção desenvolveu-se através da investigação da concepção social sobre as alterações climáticas na cidade, pela visão de seus moradores, com a aplicação de um questionário semiestruturado de percepção ambiental em relação às mudanças climáticas locais (Apêndice A) baseandose no estudo de Pascoalino e Pitton (2007). O questionário compôs-se de oito perguntas abertas e fechadas, num um total de 150 entrevistas realizadas. Destes, $51 \%$ foram do sexo masculino e os $49 \%$ restantes do sexo feminino, com idades variando de 15 a 30 anos. Todas as pessoas respondentes habitam a área urbana do município.

A análise perceptiva serviu para descrever se, na visão dos moradores, as mudanças climáticas são perceptíveis e/ou estão ocorrendo no local. A importância desta caracterização é que se pode saber onde e como os impactos poderão ser mais sentidos pelas pessoas. No caso do questionário aplicado neste trabalho, algumas perguntas também tiveram o objetivo de identificar se existe na população a consciência de que ele faz parte desse sistema e também gera impactos, bem como, de identificar se existem ações que estão sendo tomadas individualmente por estas pessoas para amenizar os impactos que elas causam sobre o clima.

\section{Resultados e Discussões}

Sobre a análise das emissões das principais fontes identificadas, a Tabela 1 apresenta o resumo do resultado das emissões estimadas para os setores.

Tabela 1 - Resultados da análise das emissões:

$\begin{array}{ll}\text { Setor } & \text { Emissão estimada } \\ \text { Transportes } & 52,890 \text { t de } \mathrm{CO}_{2} \\ \text { Resíduos } & >200 \mathrm{t} \text { de } \mathrm{CO}_{2} / \mathrm{ano} \\ \text { Efluentes } & 137,6 \mathrm{~kg} \text { de } \mathrm{N}_{2} \mathrm{O} / \mathrm{ano}\end{array}$

Pela análise das contribuições do meio urbano às mudanças climáticas é notável a significativa contribuição do setor de transportes nas emissões. O resultado final foi obtido levando-se em conta que cada carro do município percorresse $10 \mathrm{~km}$ diariamente. Apesar de possuir um perímetro urbano pequeno, o crescimento de veículos de 1.700/ano é um número muito grande, se comparado ao fato de que, no período de 2007 a 2009, a população cresceu em 2.575 habitantes.

O setor de disposição de resíduos apresentou um aumento das emissões devido à implantação do aterro sanitário municipal no ano de 2003. Visto que a drenagem dos gases neste tipo de prática é maior, faz-se necessário a implantação de queimadores que possam gerar energia para minimizar estes impactos. Como existem alguns programas de coleta seletiva em implantação no município, é possível que o volume total de resíduos no aterro venha a ser reduzido consideravelmente, amortizando assim, as emissões. No setor de tratamento de esgotos, como foram poucos os dados disponibilizados, a emissão em $\mathrm{N}_{2} \mathrm{O}$ não deixa muito clara sua influência pelo fato de não ser uma medida comparável ao $\mathrm{CO}_{2}$.

Sobre a aplicação dos questionários; quando indagados sobre a temporariedade das mudanças climáticas, $86 \%$ dos entrevistados relataram achar que estas já estão acontecendo; e 56\% acham que o fato destas mudanças estarem ocorrendo é devido às atividades antrópicas. Sobre as mudanças climáticas no local de estudo, 61\% das pessoas afirmaram que já sentem mudanças no município relacionadas ao clima, sendo que destas, as mais sentidas foram; com $26 \%$, maior freqüência de 
chuvas; $15 \%$, mudanças bruscas na temperatura ao longo do dia; $13 \%$, estações invertidas (calor no inverno e frio no verão); também com $13 \%$, frio mais rigoroso e com $12 \%$, aumento das temperaturas extremas (invernos mais rigorosos e verões mais quentes). Sobre a co-responsabilidade frente a estes acontecimentos; $63 \%$ das pessoas sentem-se responsáveis pelas mudanças no clima, contra 34\% que afirmam não sentir responsabilidade alguma e os outros 3\% sentem-se parcialmente responsáveis. Porém, quando o assunto é agir para reduzir os impactos; $57 \%$ relataram não tomar nenhuma atitude para reduzir seus impactos sobre o clima, $35 \%$ afirmam agir de maneira menos impactante e $8 \%$ tem atitudes de redução de impacto apenas às vezes. Entre as atitudes que estas pessoas tomam para redução dos impactos, a mais citada é a separação e reciclagem do lixo doméstico, seguida da economia de água e energia.

Da análise destes resultados, conclui-se que a população está consciente de que causa impactos no clima, bem como atribui ao homem a principal parcela de culpa para os eventos climáticos. Também os efeitos das mudanças climáticas já estão sendo sentidos pela população. Porém, apesar de terem observado mudanças e de se sentirem responsáveis por tais acontecimentos, a minoria dos entrevistados toma de fato alguma atitude para minimizar seus impactos. Como esta pergunta foi aberta, alguns entrevistados puderam agregar outras informações. Entre elas, de grande destaque, que reflete a aflição de todos: ao afirmarem que não estavam agindo para minimizar seus impactos, relataram que não o faziam, porém deveriam. Ou seja, até há a consciência, mas falta a ação.

\section{Conclusões e Recomendações}

O meio urbano, desde sua concepção, é caracterizado como um destruidor da natureza, seja pelo desmatamento causado para o povoamento, seja pela exploração dos recursos naturais de forma descontrolada. Estes fatos levaram a uma associação dos grandes centros urbanos à expressões como poluição, caos e desordem.

Mas com o passar dos anos e a emergência de novos paradigmas sociais, culturais e de desenvolvimento econômico, novas questões surgiram e novos estudos começaram a exigir ações da sociedade para mitigar um evento que já é parte do cotidiano: as mudanças climáticas, tendo como principal contribuinte o meio urbano. Já se torna evidente as consequências deste evento sobre os aglomerados urbanos. As cidades, em função do modelo econômico que as conformam, estão cientes, que começaram a sofrer com enchentes, deslizamentos, tempestades, estiagens, e outros fenômenos climáticos resultantes destas alterações climáticas e tornaram-se vítimas de um fenômeno que elas mesmas construíram. Desta forma, a sociedade vem dando mostras de que se tornar um inimigo do meio onde vive não é a melhor solução para enfrentar o que estaria por vir. Neste sentido, cabe a sociedade e as cidades reduzirem os problemas que causam para que os impactos que possam vir a sofrer sejam menos intensos. Evidentemente, esta compreensão, ainda que avanços na questão ambiental sejam visíveis, não se torna uma política plenamente consistente.

A conclusão que se chega ao terminar este estudo é a de que é impossível para um meio urbano não causar impacto algum e não contribuir para as mudanças climáticas. Para a mitigação dos efeitos adversos causados pelas emissões, deve haver uma resposta coordenada de todos os setores analisados. Esta resposta pode ser obtida através de programas de MDL (Mecanismos de Desenvolvimento Limpo), já conceituados neste trabalho.

No setor de transportes, não há no município ações que deveriam se tornar fundamentais, tais como programas que incentivem a renovação da frota mais antiga, incentivo ao uso do transporte coletivo, bem como acessibilidade para o uso de transportes alternativos. O automóvel está muito vinculado ao estilo de vida das pessoas, portanto, deve haver incentivos governamentais para modificar, minimamente, tal estilo, como o rodízio de automóveis e o incentivo ao uso do transporte coletivo, o que certamente implica na melhoria do próprio serviço.

No tratamento dos efluentes, a atividade anaeróbica é responsável por alta emissão de metano. A implantação de queimadores automáticos mitigaria o problema.

A emissão do setor de resíduos sólidos está diretamente ligada ao consumo da população, que deve ser objeto de ações específicas de conscientização. 
A disponibilização em aterros sanitários é um fator que facilita o controle e aproveitamento dos gases gerados, prevendo seu aproveitamento energético. Esse é um fator de mitigação das emissões, bem como pode haver a viabilização do comércio de emissões, tanto dos aterros quanto do tratamento de efluentes, são os chamados "créditos de carbono". Isso evitaria sua emissão direta para a atmosfera e traria benefícios econômicos ao município.

Pela aplicação do questionário conclui-se que a população do município já sente os efeitos das mudanças climáticas, porém, apesar de se sentirem responsáveis por tal, não tomam atitudes para minimizar seus impactos. Algumas atitudes simples, como a diminuição no uso de embalagens descartáveis, o uso de sacolas e embalagens retornáveis, além de diminuir também o uso do automóvel no dia-a-dia, são ações que podem contribuir para melhoria das condições sócio-ambientais e podem ser iniciadas sem que se impacte profundamente no estilo de vida da pessoa. Mesmo no caso do automóvel, há condições de balancear o transporte coletivo, com o transporte individual, interferindo parcialmente no estilo de vida, ensejando um processo de reeducação ambiental.

Para mitigar os efeitos negativos provenientes dos impactos das emissões no sistema climático, uma ação conjunta de MDL e conscientização populacional deve ser feita, bem como inventários precisos de emissões que indiquem onde estão as principais fontes de emissões e as principais medidas para reduzi-las. O que sugere uma possível continuidade deste estudo, com espectro ampliado, incluindo os setores industriais, bem como os que não abrangem meio urbano, como as atividades agrícolas.

\section{Questionário de Percepção Ambiental em relação às Mudanças Climáticas locais *}

Curso de Engenharia Ambiental da Pontifícia Universidade Católica do Paraná
2. Você acha que eventos extremos (ex.: períodos de muita chuva, calor intenso, longa estiagem) estão acontecendo com mais freqüência no município? Se sim, qual seria a sua explicação para esses eventos?

3. Você já vivenciou alguma situação de risco ligada a algum evento do tempo? Se sim, qual?

4. Quando você pensa em aquecimento global e mudanças climáticas, qual a primeira imagem que vem à sua mente?

5. Você acha que as mudanças climáticas afetariam:

( ) Você e sua família ( ) População brasileira ( ) População de outros países ( ) Natureza não humana ( ) Não sabe ( ) Todas as formas de vida

6. Quando você acha que as mudanças climáticas começarão a ter impactos perigosos sobre as pessoas do planeta?

( ) Já está acontecendo （） Daqui 10 anos ( ) Daqui a 20 anos ou mais ( ) Nunca será perigoso

7. Você acha que as mudanças climáticas e o aquecimento global são resultados de um processo:

( ) Natural ( ) Causado pelo homem ( ) Combinação homem + natureza ( ) Outro processo. Defina:

8. Você se sente responsável pelas mudanças climáticas? Por quê?

9. Você tem agido no sentido de reduzir seus impactos no clima? Se sim, como?

10. Você observou mudanças no município relacionadas ao clima? Se sim, quais?

Sexo: ( ) Masculino ( ) Feminino Idade: Há quanto tempo mora em Castro?

\section{Referências bibliográficas}

1. Qual a sua principal fonte de informação com relação às condições de tempo e clima?

( )Telejornais ( )Rádio ( )Jornal ( )Internet ( ) Observação direta do tempo ( ) Outra. Especifique:
ALVES, Humberto Prates da Fonseca. Metodologias de interação de dados sociodemográficos e ambientais para analise da vulnerabilidade socioambiental em áreas urbanas no contexto das mudanças climáticas In: HOGAN, Daniel Joseph; MARANDOLA Jr, Eduardo (Org.). População e mudança climática: dimensões humanas das mudanças ambientais globais. Cam- 
pinas: Núcleo de Estudos da População - NEPO/ Unicamp; Brasília: UNFPA, 2009.

CARMO, Roberto Luis do. População e Mudanças Ambientais Globais. Revista Multiciência. Campinas, 2007. Edição n 8: Mudanças Climáticas.

CARMO, L. Roberto, Dinâmica demográfica e mudanças ambientais globais: novas vulnerabilidades? São Paulo: ABEP/ UNICAMP, 2008

DETRAN/PR - DEPARTAMENTO DE TRÂNSITO DO PARANÁ. Frota de veículos por tipo e município. Disponível em: <http://www.detran.pr.gov.br/modules/ conteudo/conteudo.php?conteudo=194>. Acesso em 20 de março de 2010.

FLANNERY, Tim F. Os senhores do clima: como o homem está alterando as condições climáticas e o que isso significa para o futuro do planeta. Rio de Janeiro: Record, 2007

HALL, Jim W. et al. Engineering Cities: how can cities grow whilst reducing emissions and vulnerability? Newcastle University: Oct., 2009. Disponível em: <http://www.tyndall.ac.uk/sites/default/files/ cities_launch_brochure.pdf>. Acesso em 24 de novembro de 2009 .

HOGAN, Daniel Joseph. População e mudanças ambientais globais. In: HOGAN, Daniel Joseph; MARANDOLA Jr Eduardo (Org.). População e mudança climática: dimensões humanas das mudanças ambientais globais. Campinas: Núcleo de Estudos da População - NEPO/ Unicamp; Brasília: UNFPA, 2009.

IBGE - Instituto Brasileiro de Geografia e Estatística. População recenseada e estimada, segundo os municípios: Paraná 2007. Disponível em: <www.ibge.gov.br>. Acesso em 23 de março de 2010.

IBGE Cidades. Disponível em: <http://www.ibge. gov.br/cidadesat/topwindow.htm?1>. Acesso em 05 de abril de 2010

IPARDES - Instituto Paranaense de Desenvolvimento Econômico e Social. Caderno Estatístico do Município de Castro. 2009. Disponível em: $<$ http://www.ipardes.gov.br/cadernos/Montapdf. php? Municipio $=84160 \& b t O k=0 k>$. Acesso em 08 de março de 2010

IPCC - Intergovernmental Panel on Climate Change. Climate Change 2001: impacts, adaptation, and vulnerability. Third Assessment Report. Working Group II, 2001. Disponível em: <http://www.grida. no/publications/other/ipcc_tar>. Acesso em 10 de abril de 2010

Climate Change 2007: impacts, adaptation and vulnerability. Fourth Assessment Report Summary for Policymakers. Working Group II. Contribution to the Intergovernmental Panel on Climate Change, 2007. Disponível em: < http://www.ipcc. ch/publications_and_data/publications_ipcc_fourth_assessment_report_wg2_report_impacts_adaptation and_vulnerability.htm>. Acesso em $10 \mathrm{de}$ abril de 2010

MARANDOLA, Eduardo. Tangenciando a vulnerabilidade. In: HOGAN, Daniel Joseph; MARANDOLA Jr, Eduardo (Org.). População e mudança climática: dimensões humanas das mudanças ambientais globais. Campinas: Núcleo de Estudos da População - NEPO/ Unicamp; Brasília: UNFPA, 2009
MCT - MINISTÉRIO DA CIÊNCIA E TECNOLOGIA. Manual de Capacitação: mudança climática e projetos de mecanismo de desenvolvimento limpo. Centro de Gestão e Estudos Estratégicos. Brasília: [s.n.], 2008

Inventário Brasileiro das emissões e remoções antrópicas de gases de efeito estufa: informações gerais e valores preliminares. Brasília: [s.n.], 2009.

MELLO, Leonardo Freire de. População, consumo e mudança climática. In: HOGAN, Daniel Joseph; MARANDOLA Jr, Eduardo (Org.). População mudança climática: dimensões humanas das mudanças ambientais globais. Campinas: Núcleo de Estudos da População - NEPO/Unicamp; Brasília: UNFPA, 2009

MONZONI, Mario (Org.). Diretrizes para formulação de políticas públicas em mudanças climáticas no Brasil. São Paulo: Observatório do Clima, 2009.

MOTA, Suetônio. Urbanização e meio ambiente. Rio de Janeiro: ABES, 1999.

NUNES, Lucí Hidalgo. Mudanças climáticas, extremos atmosféricos e padrões de risco a desastres hidrometeorológicos. In: HOGAN, Daniel Joseph; MARANDOLA Jr, Eduardo (Org.). População e mudança climática: dimensões humanas das mudanças ambientais globais. Campinas: Núcleo de Estudos da População - NEPO/Unicamp; Brasília: UNFPA, 2009

OJIMA, Ricardo. Perspectivas para a adaptação frente às mudanças ambientais globais no contexto da urbanização brasileira: cenários para os estudos de população. In: HOGAN, Daniel Joseph; MARANDOLA Jr, Eduardo (Org.). População e mudança climática: dimensões humanas das mudanças ambientais globais. Campinas: Núcleo de Estudos da População - NEPO/Unicamp; Brasília: UNFPA, 2009.

PALSULE, Sudhanshu. O Desenvolvimento Sustentáve e a Cidade. In: MENEGAT, Rualdo; ALMEIDA, Gerson (Org.). Desenvolvimento sustentável e gestão ambiental nas cidades: estratégias a partir de Porto Alegre. Porto Alegre: Editora da UFRGS, 2004.

PARANÁ. Ministério Público do Estado do Paraná. Plano de gerenciamento de resíduos sólidos. Castro, 2010.

PASCOALINO, Aline; PITTON, Sandra Elisa Contri. Alterações climáticas e as percepções dos munícipes de Rio Claro - SP: da realidade ambiental ao imaginário social. Universidade Estadual Paulista: 2009 Disponível em: <http://egal2009.easyplanners.info/ area07/7321_Pascoalino_Aline.pdf>. Acesso em 15 de abril de 2010

PEREIRA, Gislene. A natureza (dos) nos fatos urbanos: produção do espaço e degradação ambiental. In: Desenvolvimento e Meio Ambiente: cidade e ambiente urbano. Curitiba: Editora UFPR, 2001. n. 3 .

RIBEIRO, Edson Leite. Cidades (in)sustentáveis: reflexões e buscas de modelos urbanos de menor entropia. João Pessoa: Universitária, 2006.

SANEPAR. Lúcia Someya - contato pessoal. Porcentagem da população atingida com coleta e tratamento de esgoto no município de Castro. Curitiba, agosto de 2010 . 
SATTHERWAITE, David Cidades e mudanças climáticas Newspaper Essay, 2008. Disponível em: <http:// www.urban-age.net/0_downloads/archive/_SA/06_ NewsPaper_Essay_Satterthwaite_por.pdf>. Acesso em 09 de agosto de 2010.

SEMA - SECRETARIA ESTADUAL DE MEIO AMBIENTE E RECURSOS HÍDRICOS DO PARANÁ. Inventário de emissão de $\mathrm{CO}_{2}$ da SEMA-PR: visando sua redução e neutralização. 2009. Disponível em: <http://www. forumclima.pr.gov.br/arquivos/File/Inventario2009. doc>. Acesso em 25 de junho de 2010.

SJOBERG, Gideon. Origem e evolução das cidades. In: Cidades: a urbanização da humanidade. 2 ed. Rio de Janeiro: Zahar, 1972. Tradução de J. Reznik.

WALKER, Gabrielle; KING, David. O Tema Quente: como combater o aquecimento global e manter as luzes acesas. Rio de Janeiro: Objetiva, 2008. 